INTERNATIONAL HIGHER EDUCATION Number 74 Winter 2014

Pages 12-14

\title{
Soaring Spain: A Dream Deferred?
}

\author{
LAURA E. RUMBLEY and LAURA HOWARD
}

Laura E. Rumbley is associate director of the Center for International Higher Education, at Boston College. E-mail: rumbley@bc.edu. Laura Howard is a lecturer at the University of Cádiz, Spain, and is currently vice president of the European Association for International Education. E-mail: laura.howard@uca.es.

As elsewhere in Europe, Spain was soaring economically and culturally during the late 1990s and early 2000s. Spanish universities were singing the anthem of modernization, based on an enthusiastic commitment to an internationalization agenda. Today, however, Spain is mired in an economic and political crisis, creating real hardship for many Spaniards, and a deep national sense of uncertainty and pessimism. This unsettling turn of events begs the question: What is the current state of internationalization in Spanish higher education; and what are the future prospects for sustained global engagement and high-quality universities in a funding-poor yet relentlessly internationalizing context?

\section{The Best-Laid Plans}

Spain has been committed to internationalizing its higher education sector in a variety of ways for more than two decades. Since 1987, Spain has consistently been a prime destination and active sending country within the European Union 
ERASMUS student mobility program. Programming coordinated by the Ministry of Foreign Affairs in the 1990s and early 2000s encouraged Spanish universities to be active in development cooperation, particularly in Latin America and North Africa.

More recently, new initiatives were launched to raise the country's higher education profile and to map an agenda for enhanced quality and relevance through international engagement. The first notable step was the establishment in 2008 of "Universidad.es" - a public foundation designed to promote Spain globally as a destination for international students and scholars.

Also, in 2008, the Spanish government released its Estrategia Universidad 2015 (EU2015), a blueprint for how to "substantially improve" the university system and "place it at a level of international excellence." EU2015 pursued excellence in key scientific and technological fields, in order to increase Spain's visibility on the European landscape, and situated internationalization at the heart of university policy in Spain. The focus on research and innovation was emphasized in the EU2015's "Campus de Excelencia Internacional" initiative, which was designed to encourage (and incentivize) universities across Spain to specialize in key areas-from nanotechnology to fine arts-so that the country might invest more strategically in the most promising campuses to cultivate international recognition in specific fields.

\section{THE HANGOVER}

Sadly, Spain's efforts to sustain these new initiatives have been disappointing. In a report published in 2011, an international team of experts (representing, among other entities, the World Bank and the International Association of Universities) 
determined that the country's progress toward the goals of EU2015 was uneven at best and made 25 specific recommendations to improve performance and overcome implementation obstacles. National funding for the "Campus de Excelencia Internacional" program terminated, leaving many campus initiatives unrealized and others dependent on limited regional funding. In June 2013, as part of a strategy to reduce public spending, the government announced that Universidad.es would be incorporated into the OAPEE, the Spanish national agency for European programs. The fact that the public authorities are unclear as to how this incorporation can be achieved (legally and practically) does not bode well for the future of Universidad.es as a clear, nimble, and effective voice for Spanish higher education around the world.

Spain can no longer sustain the ambitious international agenda for its universities, given the country's precarious political and economic circumstances. The country tumbled into a deep recession in 2008. Unemployment for citizens under age 25 was over 55 percent nationally by the end of 2012, edging even higher in the hardest-hit regions of the country. Spain's young people are more highly educated than any generation in the past; yet, these college graduates (including the increasing percentage with master's degrees) are unable to find jobs offering any permanence or wages sufficient to live independently. Indeed, anecdotes abound of young job seekers altering their resumes to show less education than they actually have, in order not to appear overqualified for entry-level positions. Many are taking advantage of the opportunity to move freely across the European Union to seek employment elsewhere (particularly to Germany). Youth emigration has increased by 41 
percent since 2008, including talk of brain drain and lost investment in the country's future.

For students still in university, paying fees has become increasingly difficult. Public university tuition levels, while rising, are not generally considered to be excessive; however, students having to repeat courses they have failed face steep tuition increases. Parents and students are squeezed as incomes shrink and the eligibility rules for study grants tighten. The situation has become so acute that Spanish universities are considering the pursuit of private donors to subsidize students in financial difficulties. Recent figures indicate that some 30,000 students may be at risk of abandoning their program without some additional support.

University faculty and staff have been affected, as well. With public spending on universities cut by over 12 percent since 2010, not only have wages been frozen, they have decreased by almost 20 percent in many cases. Promotion opportunities are minimal and many nonpermanent staff have not been renewed. The loss of staff has resulted in increased workloads for those who remain. Morale is low. An open letter published recently by a Spanish scientist emigrating to the United States to take a job at NASA lamented, "The science I will do will no longer be Spanish, nor thanks to Spain; rather I will keep doing science in spite of Spain." The Open Letter for Science in Spain movement (a consensus between the Confederation of Spanish Scientific Societies and the Conference of Spanish University Rectors, among others), is campaigning for the government to increase spending on research back to 2009 levels, in a bid to "avoid long-term damage to the already weakened Spanish research system." 


\section{STAYING THE Course}

In spite of this bleak domestic picture-or perhaps precisely because of itinternationalization is generally accepted as one of the only viable avenues for the recovery and rejuvenation of Spain's universities. Universities are seen as fundamental to achieving a "smart, sustainable, and inclusive [European] economy," and there is a very clear sense that the 21st-century Spanish university must be a globally engaged institution.

In the current constrained environment, there are limited options; but there are still opportunities. One of the prime opportunities for Spain lies in its continued attractiveness to international students. Figures from 2011/2012 indicate that Spain received more ERASMUS students than any other participating country (39,300 students, representing $19 \%$ of the year's total), and 6 of the top 10 receiving institutions in the Erasmus network were Spanish. Beyond Europe, Spain is typically among the top-three recipient countries for US study abroad participants, hosting 25,965 American participants in 2010/2011 (a $51 \%$ increase in a decade).

Although internationalization is about much more than student mobility, for the moment Spain may have to focus precisely on this "low-hanging" fruit in order to keep the internationalization momentum alive. Spanish universities should also advance effective yet low-cost strategies, including internationalization of the curriculum and other "internationalization at home" activities. As the crisis eases, however, the country should quickly pick up where it left off-implementing a vision for internationalization that enhances institutional quality, serves the national interest, and builds a university culture predicated on global engagement as a guiding principle of academic excellence. 
Above all, Spain's future internationalization must be more effectively "crisis resistant." 